\title{
Prevalence of Punctate Keratopathy of West Indians in a Colombian Referral Center and a New Name Proposed: Rice's Keratopathy
}

\author{
Virgilio Galvis $^{1,2}$, Alejandro Tello ${ }^{*, 1,2}$, Luis C. Jaramillo ${ }^{2,3}$, David Paredes ${ }^{2,3}$ and Paul A. Camacho ${ }^{3,4}$ \\ ${ }^{I}$ Department of Ophthalmology, Centro Oftalmológico Virgilio Galvis, Floridablanca, Santander, Colombia \\ ${ }^{2}$ Universidad Autónoma de Bucaramanga, Bucaramanga, Santander, Colombia \\ ${ }^{3}$ Fundación Oftalmológica de Santander (FOSCAL), Floridablanca, Santander, Colombia \\ ${ }^{4}$ Department of Investigation, Development and Technological Innovation, Fundación Oftalmológica de Santander \\ (FOSCAL), Floridablanca, Santander, Colombia
}

\begin{abstract}
Purpose: To perform a prevalence study of Punctate Keratopathy of West Indians in Colombian individuals and to propose a new name for the condition.

Methods: Prospective, population-based epidemiological study. All patients evaluated between November 1 and December 31, 2012, in the Centro Oftalmológico Virgilio Galvis and Fundación Oftalmológica de Santander (FOSCAL), Floridablanca, Colombia, with clinical findings of white corneal opacities corresponding to Punctate Keratopathy of West Indians were identified. Careful slit-lamp examination was performed for clinical diagnosis and findings were reported in the electronic medical record indicating number and location of the lesions. Prevalence was calculated for the total population, and for gender and age groups. Furthermore a literature review was performed and a new name for the condition proposed.

Results: In the whole group of patients, prevalence was $1.0 \%$. No one case was diagnosed in a patient younger than 21 year-old. No one lesion was located within $2.5 \mathrm{~mm}$ of the corneal apex. $96 \%$ of affected patients had unilateral involvement. $58.5 \%$ of eyes had a single corneal lesion; $7 \%$ of eyes had 6 or 7 corneal lesions.

Conclusion: The condition heretofore known as Punctate Keratopathy of West Indians was present in 1\% of our patients in Colombia (South America). Thus, this non-infectious, non-inflammatory, asymptomatic ailment of unknown etiology is not restricted to people of Antillean descent, or who have lived in these islands. We propose the new name "Rice's keratopathy". Age and male gender were independent risk factors for the presence of the keratopathy.
\end{abstract}

Keywords: Cornea, keratoconjunctivitis, keratopathy, punctate keratopathy of West Indians,

\section{INTRODUCTION}

Rice et al. first described Punctate Keratopathy of West Indians in 1968 as an asymptomatic condition distinguished by one or multiple small round sub-epithelial corneal lesions, usually white in color, which was found in Caribbean immigrants to the United Kingdom [1]. Its prevalence has been reported only in two publications from around 20 years ago: a series from Grenada, Lesser Antilles in the West Indies, $(6.25 \%$ rate) [2] and a letter referring to a series from northwest Ecuador with an approximate prevalence between $10-20 \%$ [3]. Although there have been no other prevalence reported studies, anecdotal information based on experience of ophthalmologists working in the Antilles, have revealed that Punctate Keratopathy of West Indians seems to be a common ocular finding on those peoples [1, 2]. This condition has also been reported in two Caucasians [2, 4], two Hindus [2], and one north American Afro-Caribbean

*Address correspondence to this author at the Department of Ophthalmology, Centro Oftalmológico Virgilio Galvis, Floridablanca, Santander, Colombia; Tel: +57 7 6392929; Fax: + 5776392626 ;

E-mail: alejandrotello@gmail.com descent [5], all of them sharing that they had previously lived in the Antilles. However, as already indicated, Punctate Keratopathy of West Indians is not limited to individuals related to those islands, and has also been found in Afroamericans and native Americans from Ecuador (SouthAmerica), and as well among mestizoes (mixed European and Native American ancestry) from Guatemala (Central America). It is noteworthy that it has not been described in North America, Africa or Asia, in patients who have not lived in the islands of the West Indies.

In our practice in Colombia with some frequency we had found the condition, and recently reported three cases $[6,7]$. We decided to determine the prevalence in our patients. Moreover, since the original name that was proposed around 47 years ago, when the condition had been seen only in Caribbean immigrants to the United Kingdom, is not accurate, we proposed a new term not suggesting that it is restricted to those human groups.

\section{MATERIALS AND METHODS}

We performed a prospective, population-based epidemiological study. Institutional Ethics Committee 
approval was obtained. This study adhered to the tenets of the Declaration of Helsinki. All patients evaluated between November 1, 2012 and December 31, 2012, in the Centro Oftalmológico Virgilio Galvis and Fundación Oftalmológica de Santander (FOSCAL), Floridablanca, Santander, Colombia, showing white corneal subepithelial lesions corresponding to Punctate Keratopathy of West Indians, were identified. These institutions provides both basic and specialized eye care services for a population of about 2 and a half million people. Standard slit-lamp examination was performed by the ophthalmology residents and ophthalmologists, all of them carefully looking for the clinical features of the condition in all the patients: corneal white dot-like lesions surrounded by a paler halo, $0.5 \mathrm{~mm}$. or less in diameter, lying at the level of Bowman's membrane and usually extending into the superficial anterior stroma [17]. When present, the number and location of the lesions were registered in the electronic medical record.

Demographic information of all patients examined was taken from the monthly electronic statistic report from the Department of Ophthalmology, Centro Oftalmológico Virgilio Galvis and Fundación Oftalmológica de Santander (FOSCAL), Floridablanca, Santander, Colombia. Patients with diagnosis of Punctate Keratopathy of West Indians were extracted from the electronic databases and distributed according to gender and age groups ( $0-10$ years old, $10-20$ years old, 21-30 years old, 31-40 years old, 41-50 years old and $\geq 51$ years old).

Prevalence rates were calculated for the total population, for each gender and for each age group. Univariate and multivariate regression analysis were performed to identify variables associated with the presence of the condition. Furthermore a literature review was performed and a new name for the condition proposed.

\section{RESULTS}

2813 consecutive patients were included. All patients were classified as mestizos by the examiners. Mean age was $48.8+/-21.6$ years (range $0-95$ years). $60.1 \%$ were women and $39.9 \%$ men. Women's mean age was $50.3+/-20.9$ years; men's mean age was $46.5+/-22.3$ years $(\mathrm{p}<0.001)$.
Prevalence of Punctate Keratopathy of West Indians according to age groups is shown in Table $\mathbf{1}$.

Prevalence in the whole group (2813 patients) was $1.0 \%$. No one case was diagnosed in a patient younger than 21 year-old. In patients between 21 and 40 year-old prevalence was $0.68 \%$, while in patients older than 40 year-old the prevalence was $1.28 \%$. Prevalence between females $(0.71 \%)$ was lower than between males $(1.43 \%)$, although the difference did not reach statistical significance $(p=0.061)$. Univariate regression analysis showed that age was significantly associated with prevalence of Punctate Keratopathy of West Indians with an odds ratio of 1.02 per year increase in age (95\% confidence interval $1.00-1.04 ; p=$ 0.038 ). A multivariate regression analysis was performed and after adjusting for sex, older age remained associated with higher prevalence of the keratopathy, odds ratio of 1.02 per year increase in age $(95 \%$ confidence interval 1.00 . $1.04 ; p=0.021)$. In the multivariate analysis after adjusting for age, men had higher prevalence than women, odds ratio 2.18 (95\% confidence interval 1.02-4.63; $\mathrm{p}=0.043$ ).

Locations of corneal lesions are shown in Table 2.

No one lesion was located centrally (within $2.5 \mathrm{~mm}$ of the corneal apex). $82.7 \%$ of the lesions were located in the periphery (located outside of an area of approximately $7 \mathrm{~mm}$ diameter). $13.7 \%$ of the lesions were located in the superior periphery and $69 \%$ in the inferior periphery of the cornea.

27 patients had unilateral involvement: 14 in his/her right eye and 13 in his/her left eye. Only one patient had bilateral lesions. $58.5 \%$ of eyes had a single corneal lesion (Fig. 1A), $34.5 \%$ of eyes had 2 or 3 lesions and only 2 out of 29 eyes $(7 \%)$ had 6 (Fig. 1B, C) or 7 corneal lesions (Table 3). Only one out of 56 lesions, stained with fluorescein (Fig. 2).

\section{DISCUSSION}

The diagnosis of Punctate Keratopathy of West Indians is based on the typical clinical appearance. The corneal lesions seem to be asymptomatic (photophobia and foreign body sensation symptoms described in one case reported by Tietze et al. most probably were associated with other ocular condition besides keratopathy of West Indians). The pathognomonic

Table 1. Prevalence of Rice's Keratopathy in a Colombian referral center.

\begin{tabular}{|c|c|c|c|c|c|c|c|c|c|}
\hline \multirow[b]{2}{*}{ Age Groups } & \multicolumn{6}{|c|}{ Gender } & \multicolumn{3}{|c|}{ Total Population } \\
\hline & $\mathrm{n}^{*}$ & $\mathbf{n}^{*}, \mathbf{R K}(+)$ & Prevalence (\%) & $\mathrm{n}^{*}$ & $\mathbf{n}^{*}, \mathbf{R K}(+)$ & Prevalence (\%) & $n *$ & $\mathbf{n} * \mathbf{R K}(+)$ & Prevalence (\%) \\
\hline $0-10$ & 77 & 0 & 0.00 & 64 & 0 & 0.00 & 141 & 0 & 0.00 \\
\hline $11-20$ & 96 & 0 & 0.00 & 109 & 0 & 0.00 & 205 & 0 & 0.00 \\
\hline $31-40$ & 113 & 0 & 0.00 & 137 & 1 & 0.73 & 250 & 1 & 0.40 \\
\hline $41-50$ & 153 & 3 & 1.96 & 244 & 2 & 0.82 & 397 & 5 & 1.26 \\
\hline$\geq 51$ & 541 & 12 & 2.22 & 942 & 7 & 0.74 & 1483 & 19 & 1.28 \\
\hline TOTAL & 1122 & 16 & 1.43 & 1691 & 12 & 0.71 & 2813 & 28 & 1.00 \\
\hline
\end{tabular}

$\mathrm{n}^{*}$ : number of patients

RK (+): Clinical findings of Rice's keratopathy. 
Table 2. Location of corneal lesions.

\begin{tabular}{|c|c|c|c|c|c|}
\hline & Lesions Location & & & & \\
\hline & Central & & & & \\
\hline & Paracentral & & & & \\
\hline & INFERONASAL & 10 & & 34.5 & \\
\hline$\stackrel{2}{=}$ & SUPERONASAL & 1 & & 3.4 & \\
\hline$\overline{\bar{z}}$ & INFEROTEMPORAL & 10 & & 34.5 & \\
\hline$\frac{1}{2}$ & SUPEROTEMPORAL & 3 & & 10.3 & \\
\hline & TOTAL (eyes) & & & & \\
\hline
\end{tabular}

features of the corneal lesions include their round, dot-like shape, $0.5 \mathrm{~mm}$. or less in diameter, white central color and paler halo, lying at the level of Bowman's membrane and usually extending into the superficial anterior stroma $[1,2]$. The corneal epithelium stays normal and almost never stains with fluorescein [1-6]: only one lesion out of 56 in our study (Fig. 2).
Table 3. Number of corneal lesion per eye.

\begin{tabular}{|c|c|c|}
\hline Number of Corneal Lesions & n (Eyes) & \% \\
\hline \hline 1 & 17 & 58.5 \\
\hline 2 & 4 & 13.8 \\
\hline 3 & 6 & 20.7 \\
\hline 6 & 1 & 3.5 \\
\hline 7 & 1 & 3.5 \\
\hline TOTAL & 29 & 100 \\
\hline
\end{tabular}

Differential diagnosis of Punctate Keratopathy of West Indians includes several ocular conditions. Patients with Superficial Punctate Keratitis of Thygeson usually have a long ophthalmological history of exacerbations and remissions of foreign body sensation, photophobia, burning and tearing, which clinical findings are very different from Keratopathy of West Indians, including between 15-20 oval or round, grouped punctate intraepithelial deposits composed of numerous discrete, fine, granular, white to gray, dot-like

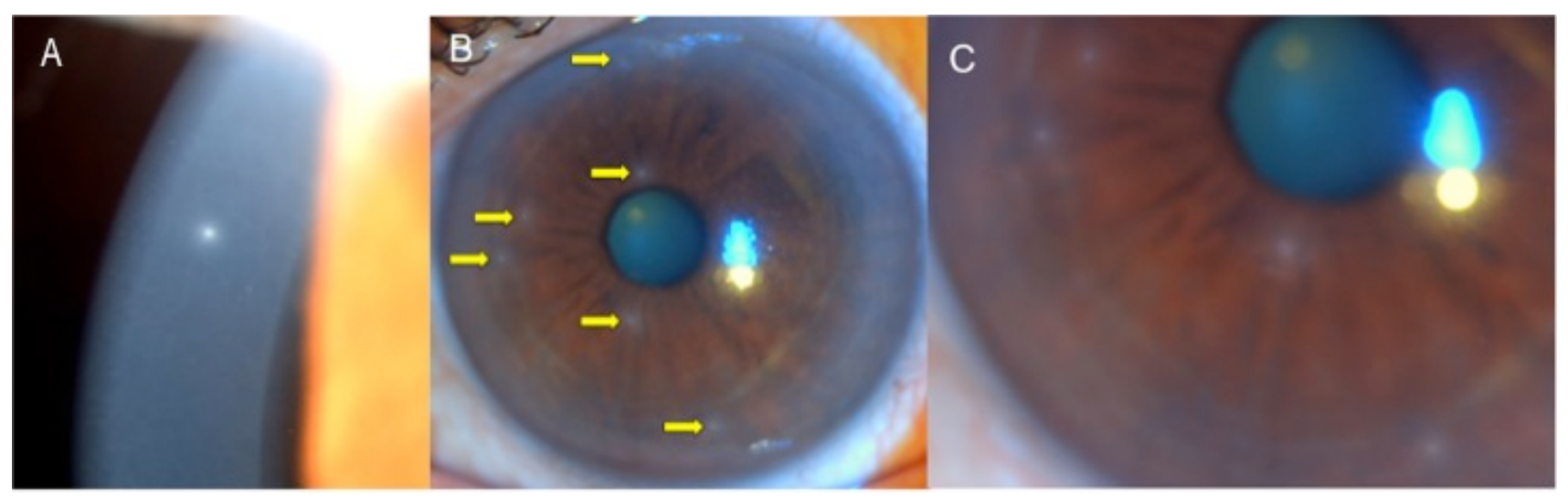

Fig. (1). (A) A typical corneal lesion of Punctate Keratopathy of West Indians (Rice's keratopathy) located in the superior periphery of the cornea. (B) Cornea showing six lesions (arrows) of Punctate Keratopathy of West Indians (Rice's keratopathy). (C) Closer view of some of the lesions.

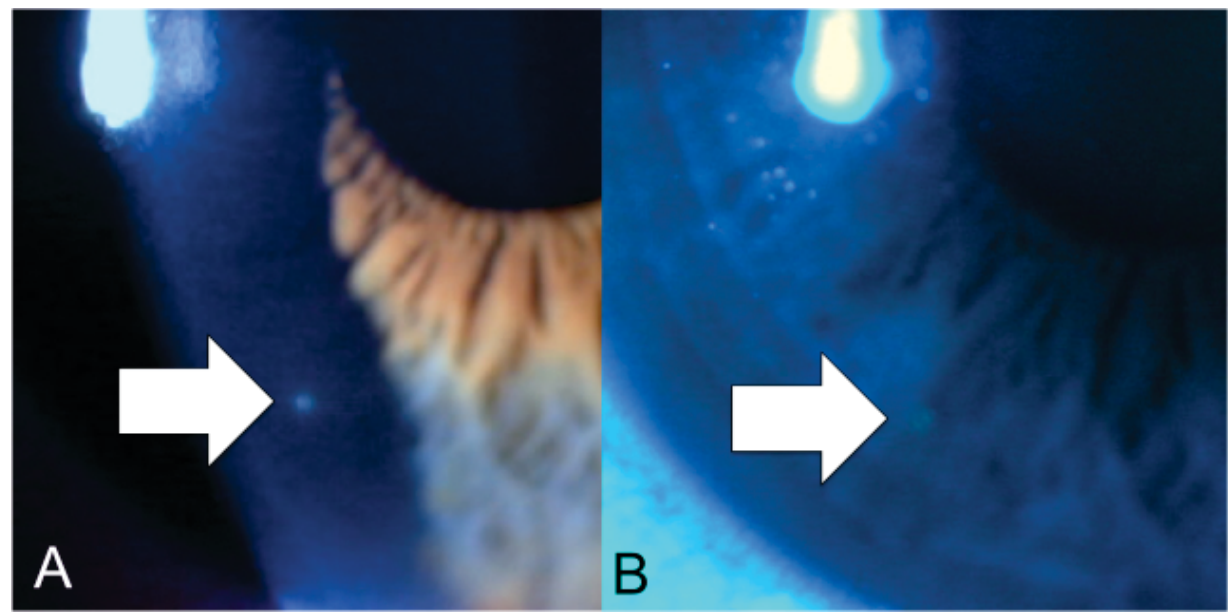

Fig. (2). (A) Corneal lesion with the features of Punctate Keratopathy of West Indians (Rice's keratopathy) showing positive staining with fluorescein (B). 
or stellate, slighty elevated opacities that usually stain with fluorescein and are bilateral. In the original description it was considered that the opacities did not affect visual acuity and faded over time, but several newer studies on series of patients have shown that in up to $50 \%$ of the cases they do not disappear and remain as subepithelial corneal opacities [8]. Individuals with infectious small corneal infiltrates can refer pain, presenting mucous discharge, an overlying corneal epithelial defect and frequently anterior chamber inflammatory reaction [9]. Contact lens wearing infiltrates, whether infected or sterile, are usually $1 \mathrm{~mm}$ or larger in diameter, not corresponding with the typical lesions of Punctate Keratopathy of West Indians infiltrates, which are $0.5 \mathrm{~mm}$ or smaller [9]. Adenoviral Epidemic Keratoconjunctivitis with stage IV and V subepithelial infiltrates usually are presented in or after the third week of presentation, usually are multiple in number with coalescence tendency, and frequently affects vision. In comparisons with Punctate Keratopathy of West Indians they are larger and without the typical well defined center and peripheral halo. History of preceding Epidemic Keratoconjunctivitis some weeks before may be elicited [10]. Other inflammatory diseases of the cornea may resemble in appearance this noninflammatory condition. One of them, Staphylococcal Marginal Keratitis (Catarrhal) usually is presented with mild to moderate pain, photophobia, foreign body sensation, and conjunctival injection. Catarrhal stromal infiltrates are usually located where the lid margin crosses the limbus (i.e. 2, 4, 8, 10 o'clock positions) and usually round lesions become oval and can coalesce into broader lesions and in the last phase of the lesion the corneal epithelium overlying the stromal infiltrates can ulcerate [11]. Epithelial Basement Membrane Dystrophy (Cogan's Microcystic Dystrophy, Map-DotFingerprint Dystrophy) is associated with polymorphous findings in the cornea; lesions may resemble maps and fingerprint lines, and frequently show microcysts. Epithelial Basement Membrane Dystrophy frequently is presented with symptoms of blurred vision and pain, usually from recurrent corneal erosion $[12,13]$.

Another entity included in the differential diagnosis is one specific kind of corneal involvement of leprosy (Hansen's disease): a superficial punctate keratitis, frequently called focal avascular keratitis [14, 15]. This distinctive corneal condition was considered, in the classical descriptions of ocular leprosy, the most common ophthalmic manifestation and pathognomonic of the disease. It is depicted as a gray milky area compromising the superior periphery of the cornea, in which are scattered multiple white lesion similar to grains of chalk, with somewhat irregular edges and variables sizes. Unlike focal avascular keratitis in Punctate Keratopathy of West Indies the epithelium that lies outside of the lesions is normal in appearance, and there is a halo surrounding the central white dot-like lesion. In addition the patient has no history of leprosy.

Another condition presenting with subepithelial opacities is the climatic droplet keratopathy [16]. This is an acquired degenerative disease characterized by the appearance of multiple tightly confluent, tiny, translucent droplet-like subepithelial deposits, mainly near the limbus, leaving a clear fringe between the limbal conjunctiva and the affected area. In advanced stages they extend throughout the interpalpebral area in a band-shaped configuration with clusters of golden subepithelial droplets of different size, some of which reach $1 \mathrm{~mm}$ in diameter. This clinical appearance is thus very different from that of Punctate Keratopathy of West Indians.

Rice et al. from the Institute of Ophthalmology, University College of London (currently cooperating closely with Moorfields Eye Hospital) originally described Punctate Keratopathy of West Indians in 26 Caribbean immigrants living in the United Kingdom, in 1968. Some patients were followed for up to 18 months and the opacities remained unchanged [1]. As we already indicate it seems to be rather frequent in the Antilles [1, 2], but other publications confirmed that the condition was not restricted to people of African-Caribbean descent, but also presented in Caucasians and Hindus who had lived in the Antilles [2, 4, 5], and in other human groups of Central and South America [3, 6, 7]. Curiously it seems to be inexistent in Caucasians, Africans or Asians who have not lived in the Antilles or Central/South America. So, for many ophthalmologists in North America, Europe, Africa and Asia this might be an unknown condition, and patients may be exposed to unneeded studies and treatments [5].

The cause of this medical entity is obscure. Several hypotheses about its etiopathology have been proposed: micro-traumas of unidentified nature [1]; seasonal air pollution due to winds carrying dust from the Sahara desert across the Atlantic ocean [2]; or agricultural related factors [2].

McLendon et al. in 128 patients presenting the condition, 147 eyes in total, found that $85 \%$ had unilateral involvement and $81 \%$ of eyes had three or fewer lesions. 21 eyes $(14.3 \%)$ had five or more dot lesions [2]. In the present study $96.4 \%$ of the patients had unilateral involvement and $93 \%$ of corneas showed three or fewer lesions. Only one eye had 6 lesions (Fig. 1B, C) and one eye 7 lesions. Rice et al. reported one case with thirteen lesions in one cornea [1].

In the present study prevalence of the condition increased with age, which is consistent with the study of McLendon et al. [2]. No child was affected in our series. Male gender was also associated with increased prevalence. These findings might suggest that exposure to environmental factors could be related to the onset of corneal injuries.

Rice et al. [1] and McLendon et al. [2] performed histopathological studies, which currently given the harmless nature of the condition are not justified, and found that the lesions consisted essentially of a sharply circumscribed area of fatty degeneration in Bowman's membrane. Rice et al. also performed electron microscopical studies and found that electron dense bodies packed into the centre of the lesion, seemed to correspond to lipid deposits differing chemically in their varying degrees of unsaturation and also to calcification within lipid globules [1].

Recently Tietze et al. performed in vivo confocal microscopy in one case in a male North-American AfroCaribbean male, and it showed a lesion containing multiple punctate opacities located above the Bowman's membrane. There were no findings of round cell infiltrate as a sign of 
inflammatory origin, and adjacent epithelial cells appeared to be normal [5].

According to our knowledge there are only two epidemiological previously published studies on this condition. In 1993 McLendon et al. reported that found it in $6.25 \%$ of 2048 patients from Grenada (Lesser Antilles)[2]. Waller et al. in a letter published in 1994 reported finding Punctate Keratopathy of West Indians between $10-20 \%$ of around 250 patients from northwest Ecuador [3].

Our study confirmed that the condition is present, although infrequent (1\%), in South America, in patients who have no relation to the Antilles. Our patients had not visited the Antilles, and were mestizos.

It is noteworthy that there are not reported cases from Europe, Asia or Africa in people who have not lived in the Antilles. In our modern globalized world undoubtedly patients with this non-infectious, non-inflammatory, asymptomatic condition of unknown etiology, originally from Central and South America, will present to ophthalmologists in Europe, Africa, Asia and North America who may never have seen this disorder, and if those specialists are not aware of its existence, those patients might be exposed to unnecessary risks of treatments and studies that are not required [5].

We contacted Dr. Noel S.C. Rice from London (United Kingdom), first author of the original description, and we agreed with him that in light of the findings of this condition in other countries of Central and South America, the name of Punctate Keratopathy of West Indians was both cumbersome and inaccurate and a change will be timely. Following current trends in taxonomy, which tend to favor clinical conditions to be named for their anatomic situation, clinical manifestations, or etiology over eponyms, a name for the disorder, based on the histopathologic description in the literature, could be "fatty degeneration of Bowman's membrane". However, this name also includes an eponym (Bowman). In order to not use an eponym we should name it "lipid degeneration of the anterior limiting lamina", but we believe that it would not be a name that ophthalmologists of the present time would find easy to remember, or that would orient them quickly on the anatomical site. Therefore, although there is controversy about the use of eponyms at present, and since the original description of the condition was made by Rice et al., which included a complete description of the condition with clinical features, histopathological and electron microscopical findings, we propose the term "Rice's keratopathy", after Dr. Noel S.C. Rice. We are convinced that this eponym will facilitate scientific communication by designating that condition with a more manageable term, and that does not suggest that it is exclusively restricted to a particular population group or geographic area.

A weakness of our study was that we did not determine the occupational history, climate exposure, and sunlight exposure of the affected population compared with the nonaffected. Additionally it would be very interesting to study the family members of the patients with the condition. Undoubtedly, additional studies on this topic are needed to achieve a more detailed understanding of possible etiology of the condition.

\section{CONFLICT OF INTEREST}

The authors confirm that this article content has no conflict of interest.

\section{ACKNOWLEDGEMENTS}

Declared none.

\section{REFERENCES}

[1] Rice NS, Jones BR, Ashton N. Punctate keratopathy of West Indians. Br J Ophthalmol 1968; 52: 865-75.

[2] McLendon BF, Kunesh MT, Graig EL, et al. West Indian punctate keratopathy. Cornea 1993; 12: 406-12.

[3] Waller SG, Proano R, Guderian R. West Indian punctate keratopathy in Ecuador. Cornea 1994; 13: 377-8.

[4] Buckley CA, Bron AJ. West Indian punctate keratopathy in a Caucasian. Br J Ophthalmol 1980; 64: 890-1.

[5] Tietze B, Kasper B, Guthoff R, et al. West Indian (Caribbean) punctate keratopathy: Clinical and in vivo confocal microscopical findings. Cornea 2011; 30: 1270-2.

[6] Galvis V, Tello A, Revelo ML, et al. Punctate keratopathy of West Indians in patients undergoing photorefractive surgery. BMJ Case Rep 2013; 2013: pii: bcr2012008192.

[7] Galvis V, Tello A, Jaramillo LC, et al. Multiple punctate subepithelial corneal lesions. Br J Ophthalmol 2013; 97: 663.

[8] Fintelmann RE, Vastine DW, Bloomer MM, Margolis TP. Thygeson superficial punctate keratitis and scarring. Cornea 2012; 31: 1446-8.

[9] Stein RM, Clinch TE, Cohen EJ, et al. Infected vs sterile corneal infiltrates in contact lens wearers. Am J Ophthalmol 1988; 105 632-6.

[10] Tabery H. Corneal epithelial changes due to adenovirus type 8 infection. Acta Ophthalmol Scand 2000; 78: 45-8.

[11] Mondino BJ. Inflammatory diseases of the peripheral cornea. Ophthalmology 1988; 95: 463-72.

[12] Cogan DG, Donaldson DD, Kuwabara T, et al. Microcystic dystrophy of the corneal epithelium. Trans Am Ophthalmol Soc 1964; 62: 213-25.

[13] Laibson PR. Recurrent corneal erosions and epithelial basement membrane dystrophy. Eye Contact Lens 2010; 36: 315-7.

[14] King EF. The eye in leprosy. Br J Ophthalmol 1936; 20: 561-9.

[15] Holmes WJ. Leprosy of the eye. Trans Am Ophthalmol Soc 19571958; 55: 145-87.

[16] Urrets-Zavalía JA, Knoll EG, Maccio JP, Urrets-Zavalía EA, Saad JA, Serra HM. Climatic droplet keratopathy in the Argentine Patagonia. Am J Ophthalmol 2006; 141: 744-6. 